\title{
La resiliencia y su influencia en los policías víctimas del conflicto armado en Colombia*
}

\section{Resilience and its influence on the police victims of armed conflict in Colombia \\ Resiliência e sua influência sobre as vítimas da polícia de conflito armado na Colômbia}

Revista LOGOS CIENCIA \& TECNOLOGÍA ISSN 2145-549X

Vol . 4. No. 1, Julio - Diciembre, 2012, pp. 137-141

\section{Resumen}

El conflicto armado en Colombia ha expuesto a civiles y miembros de la fuerza pública (militares o policías) en situaciones adversas que les cambian sus vidas en cuestión de segundos. Aparece así la resiliencia como ayuda a estos hombres y sus familias a enfrentar las situaciones desesperanzadoras que la cotidianidad de una guerra deja como marca en el presente y el futuro de los héroes de la patria. Como respuesta psicológica, la resiliencia permite que el ser humano logre ver una situación caótica desde otro plano para ayudar a enfrentarla y evitar depresiones que llegan a recaer en cuadros de suicidio.

\section{Fecha de Recepción: 13 de Marzo de 2012} Fecha de Aceptación: 15 de Mayo de 2012

* Este artículo es producto del Área de Investigación de la Escuela de Policía de la Escuela de Sumapaz "Intendente Maritza Bonilla Ruiz".

* Especialista Psicología Clínica y Autoeficacia Personal, Universidad El Bosque de Bogotá. Email: ctorrec@yahoo.com

Palabras clave: resiliencia, conflicto armado, fuerza pública.

\begin{abstract}
The armed conflict in Colombia, has exposed civilians and members of the security forces (military police) in adverse situations that will change their lives in seconds. And resilience appears to help these men and their families cope with the everyday situations that hopeless war left as a mark on the present and the future of the heroes of the homeland. As a psychological response, resilience allows the human being achieves see a chaotic situation from a different background to help you cope and avoid depressions that come to rest with pictures of suicide.
\end{abstract}

Key words: resilience, armed conflict, security forces.

\section{Resumo}

O conflito armado na Colômbia, expôs civis e membros das forças de segurança (polícia militar) em situações adversas que mudarão suas vidas em se- 
gundos. E a resiliência aparece para ajudar esses homens e suas famílias a lidar com as situações cotidianas que a guerra sem esperança deixadas como uma marca no presente e no futuro dos heróis da pátria. Como uma resposta psicológica, a resiliência permite que o ser humano consegue ver uma situação caótica de um fundo diferente para ajudá-lo a lidar e evitar depressões que vêm para descansar com imagens de suicídio.

Palavras-chave: resiliência, conflitos armados, as forças de segurança.

\section{INTRODUCCIÓN}

La violencia en Colombia ha sido un fenómeno que durante décadas ha afectado la población, pero no solo se habla de civiles sino de los hombres que a diario protegen la seguridad de nuestra nación, enfrentándose a situaciones de muerte, mutilación, secuestro y de la agonía en general que representa la guerra de una nación.

Son estas situaciones adversas las que hacen descubrir en dicha población las potencialidades para enfrentarlas y seguir adelante en un proyecto de vida; dichas potencialidades que permiten al hombre fortalecerse y superar estados críticos es lo que se conoce como resiliencia, término acuñado de la física que designa la resistencia de un material que luego de ser sometido a altas temperaturas puede volver a su estado natural.

El término resiliencia procede del latín (Kotliarenco, Cáceres y Fontecilla, 1997), de la palabra resilio, que significa volver atrás, volver de un salto, resaltar, rebotar. Los diccionarios (Kotlia-renco et al., 1997) entiende por resiliencia la resistencia de un cuerpo a la rotura por golpe. La fragilidad de un cuerpo decrece al aumentar la resistencial ${ }^{2}$. El origen del estudio de la resiliencia dentro de las ciencias de la psicología y la psiquiatría tiene su fundamento en de los esfuerzos por conocer la etiología y desarrollo de la psicopato-

Becoña, E. (2006). Resiliencia: Definición, características y utilidad del concepto. Revista de Psicopatología y Psicología Clínica, volumen 11 No, 3, 125-146. logía, tomando como referencia a los niños en riesgo de desarrollar psicopatología debido a enfermedades mentales de los padres, problemas perinatales, conflictos interpersonales, pobreza o una combinación de varios de estos factores (ver Masten, 1999; Rutter 1985, 1987). En los niños, los eventos vitales adversos más estudiados son el divorcio de los padres y estresores traumáticos como el abuso o abandono y la guerra (Garmezy y Masten, 1994). Partiendo del desarrollo que los niños tengan frente a estas situaciones y las ayudas externas que puedan tener para enfrentarlas establece el grado de resiliencia que como adulto puede llegar a tener, varios son los pilares que el niño debe cimentar para que en una edad adulta y en un ambiente adverso pueda llegar a enfrentar y soportar las situaciones que en ocasiones son ajenas y en otras son propias de su deber.

El comportamiento y profesionalismo policial hace que estos hombres y mujeres que enfrentan día a día la guerra, demuestren que la adversidad aunque toque sus vidas es parte de esa entrega a su nación y a sus semejantes, donde es necesario contar con herramientas y ayuda que permitan aflorar la capacidad resiliente que hay en cada uno de ellos. Cirulnik (1999) plantea que Resiliencia "es más que resistir, es también aprender a vivir... antes del golpe uno estima que la vida nos es debida y la felicidad también... la prueba cuando uno la sobrepasa cambia el gusto por el mundo". Ante las consecuencias que deja el conflicto, no solo en lo físico sino también en lo psicológico, la resiliencia, el deseo de sobrellevar y superar dicha situación de desesperanza hacen que el ser humano se replantee su vida buscando fortalecer lo que antes era débil.

Los pilares más relevantes que cada uno de los hombres de la fuerza pública debe cimentar durante su vida y su desarrollo profesional para obtener una resiliencia fuerte que le permita sobrellevar una situación de desesperanza ya sea propia o de alguno de sus semejantes son: Autoestima consistente, base de los demás pilares y es el fruto del cuidado afectivo consecuente del niño o adolescente por un adulto significativo.

Introspección. Es el arte de preguntarse a sí mismo y darse una respuesta honesta. Depende de la solidez 
de la autoestima que se desarrolla a partir del reconocimiento del otro.

Independencia. Se definió como el saber fijar límites entre uno mismo y el medio con problemas; capacidad de mantener distancia emocional y física sin caer en el aislamiento.

Capacidad de relacionarse. Es decir, la habilidad para establecer lazos e intimidad con otras personas, para balancear la propia necesidad de afecto con la actitud de brindarse a otros.

Iniciativa. El gusto de exigirse y ponerse a prueba en tareas progresivamente más exigentes.

Humor. Encontrar lo cómico en la propia tragedia.

Creatividad. La capacidad de crear orden, belleza y finalidad a partir del caos y el desorden.

Moralidad. Entendida esta como la consecuencia para extender el deseo personal de bienestar a todos los semejantes y la capacidad de comprometerse con valores.

Capacidad de pensamiento crítico. Es un pilar de segundo grado, fruto de las combinaciones de todos los otros y que permite analizar críticamente las causas y responsabilidades de la adversidad que se sufre, cuando es la sociedad en su conjunto la adversidad que se enfrenta. $Y$ se propone modos de enfrentarlas y cambiarlas. A esto se llega a partir de criticar el concepto de adaptación positiva o falta de desajustes que en la literatura anglosajona se piensa como un rasgo de resiliencia del sujeto (Melillo, 2002).

Cada uno de estos pilares, fortalecerá la perspectiva de vida que los hombres de instituciones como la policía y los civiles deberán tener después de ser víctimas directas o indirectas del flagelo de la violencia. Aunque reestructurar toda una vida ya creada no es fácil, existen herramientas como la resiliencia que permiten que dicho proceso aunque sea complejo, se convierta en una nueva posibilidad ante la desesperanza.

Resiliencia no es solo un término, es un camino que muestra una luz cuando la oscuridad irrumpe en la vida de los seres humanos, y en este caso particular en los hombres y mujeres que a diario se entregan por una causa, defender una nación y a su pueblo del flagelo agobiante de la violencia.

¿CÓMO SE DA LA RESILIENCIA EN LOS POLICÍAS VÍCTIMAS DE LA VIOLENCIA EN COLOMBIA?

Cuando el conflicto armado toca en lo más profundo la vida de un hombre que vistiendo con orgullo un uniforme entrega en el campo de batalla su vida, se llega a cuestionar cómo es el proceso de recuperación no solo física sino mental de estos actores principales del conflicto; en muchas ocasiones trasciende más allá del momento en que como ciudadanos recibimos o vemos la noticia, pero detrás de esta pregunta hay todo un proceso de superación de circunstancias que comprometen la vida de un individuo y sus allegados. El ser Resiliencia no es sólo un término, es un camino que muestra una luz cuando la oscuridad irrumpe en la vida de los seres humanos, y en este caso particular

en los hombres y mujeres que a diario se entregan por una causa, defender una nación y a su pueblo del flagelo agobiante de la violencia.

víctimas de un conflic-

to puede darse de diversas maneras, como las cartas de un naipe puede llegar a convertirse en una persona que es mutilada, que pierde alguno de sus sentidos o como ya lo hemos visto ser apartados de su libertad pasando gran parte de su vida en un medio hostil como lo es la selva, en condiciones infrahumanas. Cada uno de estos casos lleva a un comportamiento y a un enfrentamiento consigo mismo y con los demás que en muchas ocasiones lleva a pensar que en definitiva ya no sirve para nada, que se ha perdido mucho tiempo, o que simplemente se es un estorbo, es en este punto donde la familia y los allegados deben hacer surgir los cimientos de esos pilares que permitan enfrentar y superar las barreras que la adversidad presenta.

Hoy por hoy se presentan muchas instituciones, fundaciones y particulares que ayudan a enfrentar y aceptar la limitación, la discapacidad o retornar de 
una manera más efectiva a la vida que dejaron de vivir por culpa del secuestro. En estos casos lo que se busca y se logra es brindar y establecer relaciones interpersonales con otras personas que han pasado por situaciones similares o iguales, relaciones que permiten crear una introspección que hará que se cuestione sobre ese nuevo relato de vida que le permitirá descubrir la capacidad dentro de la limitación. La interacción con otras personas que hayan sido víctimas del conflicto (en este caso policías), hace que la resiliencia fluya con mayor efectividad, ya que se encuentra un apoyo mutuo de pares que evitan el desasosiego, la desesperanza y disipan los pensamientos de suicidio y de carga frente al resto de sociedad.

Muchos de los policías que han sufrido discapacidad durante el desarrollo de operaciones que buscan combatir a los terroristas han afirmado que la discapacidad no es un obs-
La resiliencia, entendida como la capacidad para mantener una actividad adaptativa de las funciones físicas y psicológicas en situaciones críticas, nunca es una característica absoluta ni se adquiere de una vez para siempre. táculo para vivir y desarrollarse como seres humanos en distintas áreas. Ellos ratifican que el cuerpo humano puede llegar a adaptarse de manera tal que pueden llevar una vida normal, un trabajo, practicar deporte e incorporar movimientos que antes no eran pensados. La discapacidad para estos hombres no es más que un mito cuyo significado es una limitante generalizada que opaca otras capacidades que no eran reconocidas antes de ser víctimas del conflicto, como lo son: unir esfuerzos para realizar un proyecto de gran magnitud, la empatía por el dolor de los demás, hablar en público en auditorios llenos de gente o el talento para las artesanías.

\section{RESULTADOS}

En el campo de la salud mental es común tener estereotipos y prejuicios ya establecidos frente a la respuesta del ser humano ante las adversidades, sin embargo ha sido necesario replantear el hecho que como seres individuales se reacciona de manera distinta según la situación. La resiliencia, entendida como la capacidad para mantener una actividad adaptativa de las funciones físicas y psicológicas en situaciones críticas, nunca es una característica absoluta ni se adquiere de una vez para siempre. Es la resultante de un proceso dinámico y evolutivo que varía según las circunstancias, la naturaleza del trauma, el contexto y la etapa de la vida y que puede expresarse de muy diferentes maneras en diferentes culturas (Manciaux et al., 2001). Es en este punto donde la resiliencia muestra cómo las adversidades pueden ser superadas con ayuda de los familiares y semejantes.

En el caso de los policías, un bienestar mental después de un suceso desafortunado como consecuencia de la guerra, se ha dado después de interactuar con personas en iguales circunstancias, lo que ha permitido reconocer su realidad de una manera llevadera.

La resiliencia en los policías víctimas del conflicto aumentó el conjunto de significados que definían su identidad, saliendo de la concepción lastimera, negativa o de receptor pasivo de ayudas asistenciales.

\section{REFERENCIAS BIBLIOGRÁFICAS}

Becoña, E. (2006). Resiliencia: Definición, características y utilidad del concepto. Revista de Psicopatología y Psicología Clínica, volumen 11 No. 3, 125-146

Cyrulnik, B. et al. (2004). El realismo de la esperanza. Testimonios de experiencias profesionales en torno a la resiliencia. Barcelona: Gedisa Editorial.

Melillo, A. (2004). Resiliencia. Recuperado el 3 de marzo de 2012 de http://www.elpsicoanalisis.org.ar/ numero1/resiliencia1.htm

Poseck, B., Arbelo, B. \& Vecina, M. (2006). La experiencia traumática desde la psicología positiva: Resiliencia y crecimiento postraumático. Revista Papeles del psicólogo. Volumen 27 No. 1.

Resiliencia org. 2010. Resiliencia. Recuperado el 3 de marzo de 2012 de http://www.resiliencia.org/ 
Textos/DCDFC5D6-285E-4393-840B-212CDA9AB2F.htm

Rodríguez, C. \& Mora, A. (2006). Narrativas Resilientes en Policías discapacitados por hechos violentos. Revista Pensamiento Psicológico. Volumen 2 No. 007, 41-53.
Summerfield. D. (1999). Una crítica de los proyectos psicosociales en poblaciones afectadas por la guerra basadas en el concepto de trauma psicológico. En: Pérez Sales, P. (coord.) Actuaciones psicosociales en guerra y violencia política. Madrid: Editorial Exlibris. 